\title{
A cultura como direito: reflexões acerca da cidadania cultural
}

\section{Culture as a right: reflections on cultural citizenship}

\author{
Natalia Morato Fernandes ${ }^{1}$
}

\begin{abstract}
Resumo
Neste trabalho, analisa-se o modo como a relação entre Cultura e Política tem se estabelecido no Brasil. A idéia de direitos culturais tem como matriz a declaração dos Direitos Humanos, de 1948. No Brasil, apenas a Constituição de 1988 se refere aos direitos culturais e os coloca na categoria de direitos humanos fundamentais. A proposta de cidadania cultural concebe a cultura como direito de todos os cidadãos e o Estado como agente da política cultural. Concebe a atuação na esfera da cultura como construção de uma nova cultura política, numa perspectiva transformadora e democrática.
\end{abstract}

Palavras-chave: Direitos culturais. Política cultural. Cidadania. Cultura política.

\begin{abstract}
In this paper, the relationship between Culture and Politics and its development in Brazil is analyzed. The idea of cultural rights has its origins in the declaration of Human Rights, from 1948. In Brazil, only the 1988 Constitution refers to cultural rights and places them in the category of fundamental human rights. The cultural citizenship proposal conceives culture as a right of all citizens and the State as the agent of cultural policy. This principle serves as the foundation for the development of a new political culture with democratic and transformative perspectives.

Keywords: Cultural Rights; cultural policy, citizenship, political culture
\end{abstract}

\section{Introdução}

O objetivo deste trabalho é analisar um modelo de política cultural expresso pela concepção de cidadania cultural. Paralelamente à análise dessa concepção, podemos compreender alguns traços marcantes da relação entre Cultura e Política no Brasil, em particular as concepções que pautaram a atuação do Estado brasileiro no âmbito da cultura.

Interessa-nos, de modo especial, o entendimento da cultura como direito e, nesse sentido, como objeto de planejamento e deliberação política que deve ser assegurado a todo cidadão. Para tanto, faz-se necessária uma análise retrospectiva das conquistas dos direitos civis, políticos e sociais e sua trajetória rumo à cidadania. Nesse percurso, destacamos os direitos sociais e, dentre eles, o processo de reconhecimento dos direitos culturais.

Considerar a relação entre cultura e administração também se torna indispensável quando se tem como foco a análise de um modelo de política cultural.

${ }^{1}$ Doutora em Sociologia. Professora do Departamento de Filosofia e Ciências Sociais da Universidade Federal do Triângulo Mineiro (UFTM). Grupo de Pesquisa Mídia, Educação, Cultura e Novas Cidadanias www.midedcult.wordpress.com. E-mail: natmorato@gmail.com 
Assim, traremos alguns argumentos acerca da definição do conceito de política cultural, bem como algumas considerações sobre o processo de institucionalização do campo cultural.

Acreditamos que com esse percurso teremos abordado alguns elementos que poderão proporcionar-nos um melhor entendimento da concepção da cidadania cultural, foco principal deste trabalho. Conforme explicitaremos, não se trata apenas de um modelo de política cultural, mas, essencialmente, de uma forma de atuação na esfera da cultura que visa à construção de uma nova cultura política, numa perspectiva transformadora e democrática.

\section{dos Direitos de Liberdade aos Direitos Culturais}

Conforme nos ensina Bobbio (2000, p. 476), "[...] a afirmação dos direitos do homem, antes puramente doutrinal no pensamento jusnaturalista e depois prático-política nas Declarações do fim do século XVIII, representa uma inversão radical na história secular da moral." Com essa afirmação, o autor pretende destacar que, em todos os períodos anteriores às Declarações do século XVIII (Declaração de Independência dos Estados Unidos da América, 1776 e Declaração dos Direitos do Homem e do Cidadão, 1789), havia um primado dos deveres sobre os direitos. Isto é, "os códigos morais ou jurídicos de todos os tempos são compostos essencialmente de normas imperativas, positivas ou negativas, de comando e proibições" (BOBBIO, 2000 , p. 476). Reconhece-se a correlação entre deveres e direitos, um não pode existir sem o outro, mas, as obrigações, o compromisso social, vinham antes dos direitos.

Mas, para que ocorresse a virada nessa correlação, era necessário que outra inversão acontecesse: "que o problema começasse a ser observado não mais apenas do ponto de vista da sociedade, mas também do ponto de vista do indivíduo" (BOBBIO, 2000, p. 477). Essa seria a base para o surgimento de uma nova concepção de sociedade: uma concepção individualista.

\begin{abstract}
A doutrina dos direitos naturais [...] pressupõe uma concepção individualista da sociedade e portanto do Estado, continuamente em conflito com a bem mais sólida e antiga concepção orgânica, segundo a qual a sociedade é um todo, e o todo está acima das partes. A concepção individualista custou a avançar porque foi geralmente considerada fomentadora de desuniões, de discórdias, de ruptura da ordem constituída (BOBBIO, 2000, p. 479)
\end{abstract}

Com a primazia do individual sobre o coletivo, aliado ao contexto da estruturação do Estado laico e em bases racionais, a garantia dos direitos passa a anteceder os deveres. Essa inversão se expressa, ainda, na relação entre o indivíduo e o Estado, na qual se inverte também a relação clássica entre direito e dever. No que diz respeito aos indivíduos, vêm de agora em diante os direitos e depois os deveres; no que concerne ao Estado, antes os deveres e depois os direitos (BOBBIO, 2000, p. 480)

$\mathrm{Na}$ trajetória histórica em relação à conquista dos direitos do homem, de acordo com Bobbio, é possível identificar algumas etapas:

$$
1^{\mathrm{a}} \text { etapa - Trata-se do processo de }
$$
constitucionalização dos direitos, a partir das Declarações do século XVIII, quando eles passam a ser inseridos nas constituições nacionais. "[...] que transformou uma aspiração ideal secular em um verdadeiro e próprio direito, em um direito público subjetivo, ainda que no restrito âmbito de uma nação" (BOBBIO, 2000, p. 481).

$2^{\mathrm{a}}$ etapa - Caracterizada pela progressiva extensão e reconhecimento dos direitos civis, direitos políticos e dos direitos sociais, com a ressalva de que esses direitos não nascem todos de uma vez, e nem de uma vez por todas.

A apresentação dessas categorias de direito que se tornou clássica caracteriza-os da seguinte maneira: a) direitos civis - constituem o direito ao corpo e o de ir e vir; b) direitos políticos - relacionam-se com a livre expressão de pensamento, práticas políticas 
e religiosas, enfim, a liberdade de decidir sobre a própria vida; c) direitos sociais - dizem respeito às necessidades básicas, como alimentação, moradia, saúde, entre outras. As três categorias precisam coexistir para que os direitos sejam plenos e sua articulação garanta o exercício da cidadania.

$3^{\text {a }}$ etapa - universalização dos direitos; transposição da proteção do sujeito do sistema interno para o sistema internacional - um sujeito de direito internacional $\neg-$ com a possibilidade de exigir justiça em uma instância superior à do próprio Estado. Tem como ponto de referência a Declaração Universal dos Direitos Humanos, de 1948.

$\mathrm{O}$ autor acena, ainda, para uma quarta etapa, a qual ele denomina especificação dos direitos (das mulheres, das crianças, dos idosos, dos enfermos, dos deficientes, dos doentes mentais etc.). Para ele,

[...] a expressão 'direitos do homem' já não é suficiente. É demasiado genérica. [...] Mas uma ulterior especificação tornou-se necessária à medida que emergiam novas pretensões, justificadas com base na consideração de exigências específicas de proteção, seja em relação ao sexo, seja em relação às várias fases da vida, seja em relação às condições, normais ou excepcionais, da existência humana. [...] Sim, é verdade, trata-se de um fenômeno novo; mas, olhando bem, nada mais é do que um desenvolvimento conseqüente da idéia original do indivíduo considerado em todos os seus aspectos como titular de direitos, ou seja de pretensões que lhe devem ser reconhecidas, em relação à sociedade grande ou pequena, ou até mesmo grandíssima, da qual faz parte (BOBBIO, 2000, p. 482-483).

A terceira e quarta etapas corresponderiam, portanto, ao reconhecimento dos Direitos Humanos e seus desdobramentos nas especificações a partir das categorias de gênero, fase da vida e condições de existência humana.

No entanto, Bobbio (2000, p. 483) alerta: “Que fique claro, uma coisa é a pretensão, mesmo que justificada com os melhores argumentos, outra coisa é a sua satisfação."

[...] À medida que as pretensões aumentam, a sua proteção torna-se cada vez mais difícil. Os direitos sociais são mais difíceis de proteger do que os direitos de liberdade; a proteção internacional é mais difícil do que a proteção no interior do próprio Estado [...] (BOBBIO, 2000, p. 483).
Apesar do entendimento de que os direitos sociais são importantes para o exercício da cidadania, quando compreendidos numa visão evolucionista, eles são considerados como direitos de segunda geração, pois seriam consequência e aprofundamento dos direitos civis e políticos estes considerados os direitos de primeira geração e fundamentos da liberdade.

Para a efetivação dos direitos sociais, é necessária a intervenção direta do Estado, por isso são denominados também "direitos de prestação", exatamente porque exigem, diferentemente dos direitos de liberdade, que o Estado intervenha com providências adequadas, porque não são imediata e irrevogavelmente realizáveis. Isto é, a etapa de constitucionalização não é suficiente para garantir esses direitos, faz-se necessário todo um processo de regulamentação e implementação de políticas públicas. "Poderiam ser chamados também, segundo uma velha terminologia, de direitos imperfeitos, porque são necessárias para a sua realização condições objetivas que não são encontráveis em todos os países" (BOBBIO, 2000, p. 504).

Pode-se também acrescentar que, enquanto os direitos individuais se inspiram no valor primário da liberdade, os direitos sociais se inspiram no valor primário da igualdade. São direitos que tendem, senão a eliminar, a corrigir desigualdades que nascem das condições de partida, econômicas e sociais, mas também, em parte, das condições naturais de inferioridade física (pensemos nas leis, já em vigor em todos os países democráticos, em favor dos deficientes) (BOBBIO, 2000, p. 508).

Os direitos sociais são característicos do século XX e a mobilização em torno desses direitos tornouse mais evidente a partir da Segunda Guerra Mundial. Nesse contexto, o reconhecimento e a afirmação dos direitos sociais encontram-se atrelados à concepção contemporânea de Direitos Humanos, reconstruída nesse momento como reação às atrocidades e aos horrores da guerra.

O marco da reconstrução do significado dos direitos humanos é a Declaração Universal dos Direitos Humanos, de 1948. A nova concepção é caracterizada pelos ideais de universalidade e indivisibilidade desses direitos. 
Universalidade, porque clama pela extensão universal dos direitos humanos, sob a crença de que a condição de pessoa é o requisito único para a titularidade de direitos, considerando o ser humano como um ser essencialmente moral, dotado de unicidade existencial e dignidade. Indivisibilidade, porque a garantia dos direitos civis e políticos é condição para a observância dos direitos sociais, econômicos e culturais - e vice-versa. Quando um deles é violado, os demais também o são. Os direitos humanos compõem, assim, uma unidade indivisível, interdependente e interrelacionada, capaz de conjugar o catálogo de direitos civis e políticos ao catálogo de direitos sociais, econômicos e culturais. Consagra-se, desse modo, a visão integral dos direitos humanos (PIOVESAN, 2004, p. 22).

Será, portanto, no período pós-Segunda Guerra Mundial que os Estados passarão a se debruçar sobre as questões culturais e passarão a atuar cada vez mais efetivamente, quer pela regulamentação das questões de cultura, quer pela criação de oportunidades culturais ou ainda por meio da construção de espaços culturais.

É importante lembrar que há registros bastante antigos da relação entre Cultura e Política. Porém, as análises históricas indicam que essas relações se intensificaram com o advento do capitalismo e da sociedade burguesa. No mundo ocidental moderno, o Estado passa a se ocupar efetivamente dos "negócios da cultura" ao longo no século XX, quando "as Constituições abriram um título especial para a ordem econômica, social, educação e cultura o que se deu primeiro com a Constituição Mexicana de 1917 e depois com a Constituição de Weimar de 1918, e esta com maior influência sobre as Cartas Políticas produzidas entre as duas Grandes Guerras Mundiais" (SILVA, 2001, p. 39).

No entanto, as Constituições da primeira metade do século XX referiam-seà cultura de modo vago e sintético, na maioria das vezes assegurando, como forma de direito individual, o direito à livre manifestação do pensamento, os direitos autorais e de invenção. Porém, da segunda metade do século em diante, as Constituições alargaram os horizontes da proteção da cultura, surgindo daí a idéia de direitos culturais como direitos fundamentais do homem, cuja matriz está na Declaração dos Direitos Humanos, de 1948, particularmente no art. 27:
[...] toda pessoa tem direito de tomar parte livremente na vida cultural da comunidade, de gozar das artes e de participar no progresso científico e nos benefícios que dele resultam, e toda pessoa tem direito à proteção dos interesses morais e materiais que lhe correspondem por razão das produções científicas, literárias ou artísticas de que seja autor (apud SILVA, 2001, p. 40).

Indissociável do processo de institucionalização da cultura - cujo principal expoente talvez seja a criação dos Ministérios da Cultura - está a formação e consolidação das indústrias culturais. Também a regulamentação delas caberá aos Estados-nacionais, submetidos, inclusive, a acordos internacionais.

É também no pós-Segunda Guerra Mundial com maior intensidade a partir da década de 1970 - que começa a configuração do processo conhecido como globalização. Esse fenômeno provocou a reconfiguração dos Estados-nacionais para lidar com as novas questões que surgiam nos cenários internos e nas relações internacionais, tanto em termos econômicos quanto políticos e sociais. Esse processo tem repercussões profundas no mundo da cultura - considerado até então como uma esfera cindida da economia e da política - e ele passa a ser vista com um nicho a ser explorado economicamente e, também, como forma de difundir os padrões culturais de uma dada sociedade.

Assim, nas últimas três décadas do século XX, o tema cultura foi despontando como elemento revitalizador do pensamento nas Ciências Humanas, no sentido de interpretar as novas configurações políticas, econômicas, bem como as práticas sociais (GOHN, 2008, p. 41).

No Brasil, a cultura figurará nos textos constitucionais a partir de 1934, em capítulo dedicado à educação e cultura, cujas disposições referem-se à proteção das ciências, das artes e da cultura em geral. Em 1988, a Constituição fala pela primeira vez em direitos culturais. $\mathrm{O}$ artigo 215 estabelece os direitos culturais na categoria de direitos humanos fundamentais, dispondo que “o Estado garantirá a todos o pleno exercício dos direitos culturais e o acesso às fontes da cultura nacional e apoiará e incentivará a valorização e 
a difusão das manifestações culturais." (SILVA, 2001, p. 49).

Sabemos que o tema dos direitos e da justiça social
entraram na agenda da sociedade civil e política
brasileira nas últimas décadas do século XX. Na
sociedade civil, os direitos apareceram como demanda
e reivindicação em diferentes formas: direitos sociais,
políticos, econômicos, humanos, culturais etc. Dentre
esses direitos, destacou-se o 'direito à diferença'
das denominadas minorias, que, na realidade, em
vários contextos históricos, eram e são a maioria da
população, tais como as mulheres, negros, índios
etc.. Essas demandas e reivindicações geraram vários
movimentos sociais, assim como deram origem
a inúmeras Organizações Não-Governamentais -
ONGs. O desenvolvimento desses movimentos e
ONGs ajuda a unir os dois termos: cultura e direitos
e construir uma nova cultura política na sociedade,
a partir da redefinição de valores, símbolos e
significados, num jogo de interação e reciprocidade
entre o instituído e o instituinte (GOHN, 2008, p. 41).

No cenário político nacional recente é possível perceber a seguinte periodização nos debates sobre os direitos e da justiça social:

- Direitos humanos e políticos - ao final do regime militar;

- Direitos sociais - no período de transição para a democracia, especialmente na fase da Constituinte;

- Direitos culturais, aliados ao tema da justiça e da equidade social - final dos anos 1990 e início do século XXI.

[...] O campo dos direitos culturais abrangem temas, questões e problemáticas relacionadas à múltiplas dimensões do ser humano tais como gênero, raça, etnia, religião, faixas etárias, nacionalidades. Abrange também o produto e a obra produzida por esses seres humanos em suas relações sociais tais como as formas e os meios de comunicação (em que a linguagem tem sentidos e significados peculiares segundo as dimensões anteriormente citadas); expressões artísticas, manifestações culturais e folclóricas locais, regionais e nacionais; práticas de ensino e aprendizagem; esporte e lazer. O campo dos direitos culturais penetra também no modo e estilo de vida cotidiana (trabalhar, comer, vestir, habitar, cuidar da saúde do corpo e da mente; o relacionamento com amigos, colegas de trabalho, parentes, vizinho e a comunidade próxima); assim como nos valores, formas de pensar e agir, e concepções de mundo, que os seres humanos têm elaborado ao longo dos séculos e milênios, como, por exemplo, concepção de tempo e espaço, valores aspirados como universais como igualdade, liberdade, fraternidade, solidariedade etc. Hábitos e comportamentos também relacionam-se diretamente com os direitos culturais, pois o respeito à natureza, ao acervo e patrimônio arquitetônico e artístico-cultural da humanidade, aos símbolos, signos e códigos culturais de uma nação os culto e as crenças construídos pelos antepassados, dentre outros, formas perpassadas por práticas de direitos e deveres orientados por matrizes com enraizamento na cultura (GOHN, 2008, p. 42-3).

\section{Política Cultural: uma Articulação entre Coisas Distintas}

A definição do conceito de política cultural envolve ambigüidades, pois pretende reunir num único conceito coisas que poderiam estar em oposição: "Se cultura é liberdade e política é organização [administração], como entendermos uma junto à outra?" (FEIJÓ, 1992, p. 9). Política cultural seria, então, uma articulação entre coisas distintas, serviria tanto para o controle da cultura quanto para a sua democratização.

Não se pode confundir cultura a serviço da política com política a serviço da cultura. Da mesma forma que pode existir política para a proibição, o cerceamento, o direcionamento, a imposição, também pode existir a organização para o incentivo, para a criação, para o esclarecimento, enfim, para uma elaboração cultural que supere a própria política que the deu origem (FEIJÓ, 1992, p. 9).

$\mathrm{O}$ exame de algumas experiências históricas nos fornece exemplos tanto de uma situação quanto de outra. Mas isso nos colocaria numa posição maniqueísta de ou isto ou aquilo, quando a questão nos parece muito mais ampla e mais complexa. Política cultural refere-se, então, à ação de organização da cultura - seja por parte do Estado (em seus diferentes níveis - federal, estadual e municipal) ou de particulares (instituições públicas ou privadas, empresas, organizações não governamentais etc.).

Uma interpretação corrente, porém limitada, desse conceito é a que considera como Política Cultural somente as ações organizadas em torno 
da questão artística (artes plásticas, música, teatro, museus etc.), quando a cultura envolve níveis mais complexos (cultura popular, indústria cultural). $\mathrm{O}$ equacionamento das diferentes modalidades de expressões simbólicas e culturais, sem predomínio de uma sobre as outras, ou mesmo das imposições de objetivos políticos sobre os culturais, temse configurado como o principal desafio para a formulação de políticas na área da cultura.

Foram poucos os autores que se debruçaram sobre a tarefa de explicitar o conceito de política cultural ,e a maioria deles o fez segundo uma perspectiva histórica, recobrindo amplo período que tem como marco inicial a Grécia antiga.

\begin{abstract}
A política cultural é tão antiga quanto o primeiro espetáculo de teatro para o qual foi necessário obter uma autorização prévia, contratar atores ou cobrar pelo ingresso. Tão velha, em outras palavras, quanto a Grécia antiga, mais velha que o Império Romano, berço de Mecenas, incentivador da arte e da cultura. No mínimo, tão antiga quanto a Renascença italiana e o dinheiro dos Médici, sem o qual um estoque majestoso de obras-primas não teria emergido para os olhos admirados de sucessivos séculos. Ou, ainda, antiga como a Revolução Francesa, que abre 'ao público' as portas das bibliotecas e dos museus e faz surgir a política cultural como um projeto verdadeiramente social. Em última instância, a política cultural tem no mínimo a idade das iniciativas do escritor e militante André Malraux, no final dos anos 50 deste século $[\mathrm{XX}]$ que se encerra, das quais resultou a criação do ministério da cultura na França e a implantação de uma sólida malha cultural que irriga aquele país de uma maneira, se não única, sem dúvida notável (COELHO, 1997, p. 9).
\end{abstract}

Para o autor, Política Cultural constitui "uma ciência da organização das estruturas culturais" e, nesse sentido,

[...] é entendida habitualmente como programa de intervenções realizadas pelo Estado, instituições civis, entidades privadas ou grupos comunitários com o objetivo de satisfazer as necessidades culturais da população e promover o desenvolvimento de suas representações simbólicas (COELHO, 1997, p. 293).

Com essa definição, o autor amplia o conceito de Política Cultural em relação a outras interpretações que a restringe principalmente à ação do Estado na organização da cultura. Um ponto parece ser consensual: o conceito possui caráter de ação, de intervenção social - ainda que não exclusivamente por parte do Estado.

Numa tentativa de sistematização, T. Coelho propõe a seguinte definição para o conceito de Política Cultural:

Sob este entendimento imediato, a política cultural apresenta-se assim como conjunto de iniciativas, tomadas por esses agentes, visando promover a produção, a distribuição e o uso da cultura, a preservação e a divulgação do patrimônio histórico e o ordenamento do aparelho burocrático por elas responsável. Essas intervenções assumem a forma de: Normas jurídicas, no caso do Estado, ou procedimentos tipificados, em relação aos demais agentes, que regem as relações entre os diversos sujeitos e objetos culturais; E intervenções diretas de ação cultural no processo cultural propriamente dito (construção de centros de cultura, apoioamanifestaçõesculturaisespecíficas, etc.). Como ciência da organização das estruturas culturais, a política cultural tem por objetivo o estudo dos diferentes modos de produção e agenciamento dessas iniciativas, bem como a compreensão de suas significações nos diferentes contextos sociais em que se apresentam. (COELHO, 1997, p. 293).

Certamente, essa definição é importante do ponto de vista de quem busca a definição de um campo (no sentido bourdieusiano do termo), pois abarca todo complexo de relações de concepção, implementação/produção, acesso/consumo, estrutura, legislação, etc. No entanto, faz-se necessária ainda, uma análise crítica das implicações do processo de institucionalização da cultura e sua conseqüente administração. Para tanto, recorremos às contribuições de Theodor Adorno, em particular sobre as noções de indústria cultural e cultura administrada.

Theodor Adorno dedicou parte significativa de sua produção teórica à análise do processo cultural da sociedade na fase do capitalismo tardio. Uma de suas principais contribuições para o exame deste assunto está no ensaio, escrito em parceria com Max Horkheimer, "A indústria cultural: o esclarecimento como mistificação das massas" que compõe o livro Dialética do Esclarecimento, publicado em 1947.

Nesse ensaio, os autores explicitam o processo de imbricação entre cultura e economia, bem como seus desdobramentos na esfera da política, que 
caracterizam o atual estágio do desenvolvimento capitalista. Evidentemente, os estudos sobre cultura e economia não se iniciam neste momento, mas as interpretações anteriores tendiam a considerar a cultura como uma esfera cindida da economia, como espaço de refúgio ou de contestação para os problemas da vida moderna. Outros viam nas transformações do modo de produção de bens culturais - cada vez menos artesanal e mais técnicoindustrial - a possibilidade de, por meio da produção em larga escala, atingir um número maior de pessoas e assim democratizar a cultura. É nesse contexto que surge a expressão cultura de massa, que tentava transmitir a idéia de uma cultura surgida das massas. Ora, é em particular contra esse argumento que se destina o ensaio de Adorno e Horkheimer. Para desvelar essa argumentação, cunham o conceito de indústria cultural e demonstram, ao contrário do que pretendiam os "advogados da coisa", tratarse da imposição da lógica econômica à cultura. Isto é, o modo de produção industrial, pautado no modelo fordista, passava a ser aplicado a produtos simbólicos e isso resultava de nova forma de organização do capital.

Outro texto de Adorno a respeito das circunstâncias que envolvem o processo cultural é Cultura e Administração. De extrema relevância para as questões examinadas neste trabalho, o ensaio é emblemático desde sua primeira frase: "Quien habla de cultura habla también de administracion, quiéralo o no". Essas palavras, vindas de Adorno, podem causar estranheza, particularmente àqueles acostumados a rotulá-lo como pessimista ou elitista, defensor da cultura erudita, de acesso restrito apenas aos que dominam seus códigos. Esse texto mostra exatamente que as análises adornianas sobre o mundo da cultura não são descoladas dos demais aspectos da vida social, como a política e a economia.

O primeiro aspecto salientado pelo autor é a abrangência da palavra cultura e da relação tensa estabelecida com a administração:
El reunir bajo la palabra única de cultura cosas com denominador tan distinto como filosofía e religión, arte y ciencia, formas del modo de vivir y moralidad $\mathrm{y}$, finalmente, el espíritu objetivo de uma época, traiciona de antemano la mirada administrativa, que, desde lo alto, acumula, reparte, pondera, organiza (ADORNO, 1971, p. 69).

Talvez essa contraposição entre as duas esferas tenha sido construída historicamente a partir do entendimento que se tinha da palavra cultura: "tendría que ser lo más alto y puro, lo que no este manoseado ni aderezado mediante ninguna consideración táctica ni técnica [...] La cultura sería la manifestación de la essencia humana pura, sin consideracion de las unidades funcionales de la sociedad." (ADORNO, 1971, p. 70). Adorno referese a essa concepção como um conceito ingênuo de cultura, que, para seus defensores, certamente provocaria estranheza pensar a cultura como algo administrado (ou administrável).

No entanto, surgiria daí um paradoxo: por um lado, "quanto mais se fizer pela cultura, pior para ela", pois isto significaria subordiná-la, classificála, submetê-la a uma lógica que é exterior a ela. Por outro lado, "pero si se la abandona a si misma, no solo queda amenazado todo lo cultural com la perdida de la possibilidad de ejercer um efecto, sino con la perdida de la existencia." (ADORNO, 1971, p. 70). Sua postura é bastante clara quanto a esta questão:

Ni hemos de aceptar sin crítica el concepto ingenuo de cultura, hace ya mucho cruzado por ideas propias de negociaciones, ni - denegado conservadoramente - hemos de quedarnos con lo que le ocurra en la época de su organización integral. (ADORNO, 1971, p. 70).

Adorno desenvolve análise sobre o processo de burocratização ocorrido na sociedade moderna retomando, e criticando em alguns momentos, a análise weberiana para enfatizar como essa tendência se expande para o mundo da cultura. Um dos principais problemas identificados é o dos critérios gerais das normas administrativas, que não observam as especificidades da "coisa" a ser administrada, pelo contrário, tendem a apagálas. Não se trata de "negar" a administração da 
cultura, mas de observar que não se pode fazê-lo com as normas gerais da administração tendentes à homogeneização, isto é, não importa o que será administrado, os princípios serão sempre os mesmos. Adorno adverte que, no caso da cultura, é preciso considerar suas especificidades, a sua "razão imanente": não se deve tratá-la com normas que não lhes são imanentes, "que não tem nada a ver com a qualidade de seu objeto".

Para Adorno, a administração da cultura deve ser exercida por pessoas especializadas e deve-se estar atento aos argumentos aparentemente democráticos (de "dar" ao povo o que ele quer), bem como aos jogos de interesses políticos e mercadológicos.

Una política cultural socialmente no ingenua tiene que mirar hasta el fondo de este conjunto complejo, sin temer ante la amonestación de las mayorías. Indudablemente, no es possible eliminar mediante una simple política cultural la contradicción entre el orden democrático y la consciencia existente de hecho em quienes tanto están retenidos a consequencia de las condiciones materiales como mantenidos hacia la minoría de edad; pero la democracia otorga, con todo, cierta igualación gracias a la representación, a la que, en definitiva, deben también los expertos su legitimidad para la administración de los asuntos culturales: permite impedir las maniobras que sirven a la barbárie, merced a que éstas corropen los pensamientos de calidad objetiva mediante la malfamada apelación a la volunté de tous. Las palabras de Benjamin acerca del crítico - que tiene que sostener los intereses del público contra el público - son aplicables a la política cultural. Y el experto está también al servicio del público (ADORNO, 1971, p. 95).

No entanto, onde encontrar pessoas qualificadas para essas atividades senão entre aqueles ligados ao mundo da cultura?

No existe ninguna pura inmediateidad de la cultura: allí donde los hombres la consumen con gusto como un bien de consumo manipula a los hombres; el sujeto se convierte en sujeto de cultura únicamente pasando a tráves de la mediación de las disciplinas objetivas, y su procurador en el mundo administrado es en todo caso el experto. Desde luego, habría que encontrar expertos cuya autoridad fuese realmente la de la cuestión, y no la fuerza meramente personal del prestigio o de la sugestión. Debería, incluso, ser um experto quien decidise quiénes son expertos (círculo fatal). La relación entre administración y expertos no es solo necesidad, sino también virtud: abre la perspectiva de proteger las cosas culturales de la esfera de dominio del mercado o del pseudomercado, esfera que hoy, irremisiblemente, es algo casi truncado. [...] Quien impertérritamente, con consciencia crítica, se vale de los medios administrativos y de las instituiciones, hace siempre possible que se llegue a realizar algo de lo que de otro modo no sería sino cultura administrada; y las mínimas diferencias que con respecto a lo siempre igual a si mismo se abren ante él representan, como de costumbre desvalidamente, la diferencia en torno al todo: em la diferencia misma, desviación, está concentrada la esperanza (ADORNO, 1971, p. 9597).

Adorno salienta a especificidade da formação cultural, que deve ser mediada por especialistas e não pelo simples consumo de produtos culturais. É o especialista que possui autoridade para atuar no meio cultural, essa autoridade deveria originar-se não de seu prestígio ou posição social, mas de seus conhecimentos, de sua formação na área. "Deveria, inclusive, ser um especialista quem decidisse quem são especialistas (círculo fatal)". Essa caracterização parece se aproximar dos apontamentos de Bourdieu sobre a constituição do campo artístico. O processo de autonomização do campo caracteriza-se por estabelecer distinções dos outros campos que compõem o espaço social, bem como afirmar as habilidades específicas que os agentes inseridos nesse campo devem apresentar.

A relação entre a administração da cultura e os especialistas da área numa sociedade cada vez mais dominada pelo mercado tornou-se mais que uma necessidade, uma virtude, para que haja ainda uma brecha contra a dominação total do mercado. Fica a esperança de que o especialista, valendo-se dos meios da administração e das instituições, possa fazer algo mais pela cultura do que abandoná-la à própria sorte.

\section{Cidadania Cultural: a Cultura como Direito}

A forma de atuação do Estado com relação à cultura ganhou, durante a década de 1980 no Brasil, novos contornos expressos em duas tendências principais: a de "cultura e mercado" 
e a de "cidadania cultural". No caso da primeira tendência, o Estado aparece como mediador das relações entre produtores culturais e empresas ou pessoas físicas interessadas em financiar projetos culturais e serem beneficiadas por abatimento em impostos. É neste contexto que se insere a discussão sobre as Leis de incentivo à cultura. A proposta de "cidadania cultural" concebe a cultura como direito de todos os cidadãos e o Estado como agente da política cultural.

As principais considerações a respeito de políticas de cultura pautadas pelo princípio da cidadania cultural foram realizadas por Marilena Chauí. Essas considerações partem de alguns debates esboçados no interior do Partido dos Trabalhadores e, principalmente, da experiência da autora à frente da Secretaria Municipal de Cultura da cidade de São Paulo, durante a gestão da prefeita Luiza Erundina (1989 - 1992).

As discussões internas do Partido dos Trabalhadores acerca das propostas que deveriam nortear o tratamento das questões culturais originaram o documento Política Cultural, assinado por Marilena Chauí, Antonio Candido, Lelia Abramo e Edelcio Mostaço e encaminhado à Executiva Nacional do PT. O foco da discussão é a relevância da cultura no projeto de transformação da sociedade, em uma perspectiva democrática e socialista. A cultura é apresentada como um campo que possibilita as transformações sociais pelo significado de resistência que ela tem para as classes dominadas.

O documento, desde o início, aparece como um protesto de seus autores à pouca atenção dispensada pelo Partido às questões culturais:

Embora pareça secundária ou mesmo irrelevante, a questão cultural deveria ser considerada uma das prioridades do Partido dos Trabalhadores quando se leva em conta o papel da cultura seja como fator de discriminação sócio-política, seja como instrumento de dominação ideológica, seja como forma de resistência das classes dominadas, seja, enfim, como forma de criação com potencial de emancipação e de liberação histórica. Se cultura fosse algo de menor importância, seria incompreensível a atenção que lhe é dada pelo Estado contemporâneo e a expansão dos meios de comunicação de massa como instrumento de legitimação da ordem vigente e de conformismo social e político (CHAUI et al., 1984, p. 5).

Os autores fazem explanação breve e geral sobre a constituição do Estado Moderno e suas formas de controle e dominação social, para demonstrar a maneira pela qual, historicamente, o aperfeiçoamento do aparato burocrático levou à especialização das funções políticas e, consequentemente, ao distanciamento da participação popular ou mesmo das instâncias de representação, como os partidos políticos. O que pretendem é, a partir da perspectiva marxista, lembrar a associação entre Estado e capital para a manutenção da ordem estabelecida e alertar para o seguinte aspecto:

[...] um dos instrumentos mais poderosos e eficazes da legitimação do Estado contemporâneo é a política cultural e a indústria cultural, encarregadas de disseminar, conservar e difundir a ideologia da classe dominante. A política cultural diretamente efetuada pelo Estado se realiza nas escolas (do pré-primário às universidades), nos laboratórios e centros de pesquisa científica e artística, nos planos nacionais de educação e de cultura, nos museus, na literatura oficial e em todas as empresas nacionais de cultura. A indústria cultural (que pode ser estatal ou não) se realiza pelos meios de comunicação de massa - imprensa, rádio, televisão, propaganda, serviços editoriais, discos e artes audiovisuais. Evidentemente, as finalidades da política cultural e da indústria cultural são as mesmas, isto é, a conservação da ideologia dominante, porém, a política cultural pode oferecer-se como política nacional que interessa à nação e à sociedade como um todo, enquanto a indústria cultural se oferece diretamente determinada pelo jogo do mercado e da competição. A política cultural pode aparecer como incentivo à produção cultural, enquanto a indústria cultural se baseia exclusivamente no consumo dos chamados bens culturais. (CHAUI et al., 1984, p. 8-9).

Elaborado num momento em que o Partido se estruturava e ainda não era governo, o texto assume especial importância por apresentar elementos das principais diretrizes de política cultural, contendo recomendações e sugestões ao Partido, no sentido de que a ele caberia "discutir, elaborar e pôr em prática uma política cultural capaz de questionar pela raiz as políticas culturais existentes" (CHAUI et al.,1984, p. 9).

No entanto, ao assumir a administração do município de São Paulo, o Partido dos Trabalhadores 
viu-se diante da necessidade de especificar sua estratégia de atuação no campo da cultura. Aliás, como esclarece Chauí (1995), o desafio era ainda maior, pois buscava-se lançar as bases de uma nova cultura política.

\begin{abstract}
O desafio imposto pelas condições históricas (sociais e econômicas) e pelo imaginário político (fortemente conservador, na cidade de São Paulo), exigia em cada campo de atividade governamental fossem realizados três trabalhos simultâneos: a mudança na mentalidade dos servidores públicos municipais, a de definição de prioridades voltadas para as carências e demandas das classes populares e a invenção de uma nova cultura política. (CHAUÍ, 1995, p. 71).
\end{abstract}

Para a área da cultura, especificamente, o desafio estava em estabelecer diretrizes políticas sem ter como referência uma tradição claramente definida. A indicação dos procedimentos a serem adotados era norteada pela idéia de que se deveria definir "uma política cultural" e não um conjunto de atividades e serviços culturais. Nesse sentido, serviram como referências, por um lado, algumas experiências anteriores, em especial as de Mário de Andrade e de Sábato Magaldi, e, por outro lado, algumas tradições que se pretendia recusar, visto que representavam "o modo como a tradição oligárquica autoritária opera com a cultura, a partir do Estado" (CHAUÍ, 1995, p. 81).

Quatro tem sido as principais modalidades de relação do Estado com a cultura, no Brasil. A liberal, que identifica cultura e belas-artes [...]. Na qualidade de artes liberais, são vistas como privilégio de uma elite escolarizada e consumidora de produtos culturais. A do Estado autoritário, na qual o Estado se apresenta como produtor oficial de cultura e censor da produção cultural da sociedade civil. A populista, que manipula uma abstração genericamente denominada cultura popular, entendida como produção cultural do povo e identificada com o pequeno artesanato e o folclore, isto é, com a versão popular das belas-artes e da indústria cultural. A neoliberal, que identifica cultura e evento de massa, consagra todas as manifestações do narcisismo desenvolvidas pela mass mídia, e tende a privatizar as instituições públicas de cultura deixando-as sob a responsabilidade de empresários culturais. (CHAUÍ, 1995, p. 81).

A partir da recusa desses modelos buscou-se estabelecer os elementos norteadores da política cultural da Secretaria Municipal de Cultura de São Paulo:

Assim, procuramos recusar o controle estatal sobre a cultura e a monumentalidade oficial da tradição autoritária, garantindo contra ela que o Estado não é produtor de cultura. Procuramos recusar a divisão populista entre cultura de elite e cultura popular [...] enfatizando uma outra diferença, aquela existente entre a produção cultural conservadora, repetitiva e conformista (que pode estar presente tanto no elitista como no popularesco) e o trabalho cultural inovador, experimental, crítico e transformador (que pode existir tanto nas criações de elite quanto nas populares). Enfim, procuramos recusar a perspectiva neoliberal, garantindo independência do órgão público de cultura face às exigências do mercado e à privatização do que é público, enfatizando por isto a idéia de Cidadania Cultural, isto é, a cultura como direito dos cidadãos, sem confundir estes últimos com as figuras do consumidor e do contribuinte. (CHAUÍ, 1992, p. 14).

De acordo com a autora, a Secretaria Municipal de Cultura estabeleceu como diretriz política a "cidadania cultural", pela qual se entende "a cultura como direito dos cidadãos e como trabalho de criação" (CHAUÍ, 1992, p. 12). Em outro momento a definição do conceito é apresentada de forma mais ampla, visto que o direito à cultura é compreendido a partir dos seguintes aspectos:

- direito de produzir cultura, seja pela apropriação dos meios culturais existentes, seja pela invenção de novos signos culturais;

- o direito de participar das decisões quanto ao fazer cultural;

- o direito de usufruir dos bens da cultura, mediante a criação de locais e condições de acesso aos bens culturais para a população;

- o direito de estar informado quanto aos serviços culturais e as possibilidades de dele participar ou usufruir;

- $\quad$ o direito à formação cultural e artística pública e gratuita nas Escolas e Oficinas de Cultura do Município;

- $\quad$ o direito à experimentação e à invenção do novo nas artes e nas humanidades;

- $\quad$ o direito a espaços para reflexão, debate e crítica; 
- $\quad$ o direito à informação e à comunicação (CHAUÍ, 1992, p. 15-16).

Esclarece, também, as noções de cultura que norteiam tal conceito:

[...] A cultura é por nós entendida sob um duplo registro: no sentido antropológico amplo de invenção coletiva e temporal de práticas, valores, símbolos e idéias que marcam a ruptura do humano em face das coisas naturais com a instituição da linguagem, do trabalho, da consciência da morte e do tempo, do desejo do diverso da necessidade, do poder como diverso da força e da violência, do pensamento como diferenciação entre o necessário e o possível, [...], a determinação ética da existência pela liberdade e pela culpa, à determinação política da existência pelo trabalho realizado sobre as diferenças e conflitos sociais. Neste primeiro sentido a cultura é um dado ou um fato e somos todos seres culturais. Num segundo registro ou num segundo sentido, tomamos a cultura como trabalho - entendido por trabalho o movimento pelo qual os seres humanos são capazes de uma relação com o ausente e o possível, são capazes de negar as condições imediatas de sua experiência e são capazes de criar o novo como plenamente humano. Tomamos o trabalho cultural como criação das obras culturais, pela capacidade humana de ultrapassar os dados imediatos da experiência e dotá-las de um sentido novo trazido pela reflexão e pela leitura/ escrita - trata-se das obras do pensamento - ou trazido pela sensibilidade, pela imaginação, pela inteligência e pela invenção de formas e conteúdos - trata-se das obras de arte. Neste segundo sentido, a cultura não é um dado, mas um valor e uma avaliação que os humanos fazem de seu próprio mundo (CHAUÍ, 1992, p. 39).

Essa definição deveria inspirar novo tipo de mentalidade e prática cultural, tanto por parte dos cidadãos como dos funcionários da Secretaria Municipal de Cultura. As diretrizes definidas para a política cultural do município visavam a alterar o modo de concepção, a prática e a organização da cultura como serviço público e, para tanto, também deveria ser alterada a relação do poder público com a população.

Nossa política cultural tem-se proposto a enfrentar o desafio de admitir que a cultura é simultaneamente um fato e um valor, a enfrentar o paradoxo no qual a cultura é o modo de ser dos humanos e, no entanto, precisa ser tomada como um direito daqueles humanos que não podem exercer plenamente o seu ser cultural - no caso, a classe trabalhadora (CHAUÍ, 1992, p. 39).
Em vários momentos, a autora relata as dificuldades encontradas para implementar a política da cidadania cultural: dificuldades em relação à burocracia (própria dos órgãos de administração); resistência dos funcionários em trabalhar de acordo com as novas perspectivas; dificuldades com relação ao legislativo, para a aprovação de projetos de lei da cultura, "sempre considerados secundários"; dificuldades com relação a outras esferas da administração municipal - particularmente no tocante à questão orçamentária; além da precariedade da estrutura física em que se encontravam os espaços culturais do município. (CHAUÍ, 1992). Apesar dos percalços, na avaliação da autora, o saldo foi positivo:

\begin{abstract}
Acreditamos, no entanto, que embora as dificuldades não tenham sido plenamente superadas (quatro anos não são suficientes para modificar hábitos enraizados nas condições econômicas, sociais e políticas da cidade), elas o foram parcialmente e as melhores provas disto estão nas audiências para o orçamento de 1993 [...] e no conjunto de projetos voltados para a pluralidade e diferenças culturais da cidade, expressas nos movimentos sociais e populares (CHAUÍ, 1992, p. 28).
\end{abstract}

A política de cultura adotada pela Secretaria Municipal de Cultura na gestão 1989 - 1992 tornouse referência nacional. Vários de seus projetos e programas foram adotados por diversas cidades e Estados do país. Além disso, seu princípio norteador - a cidadania cultural - é considerado contraponto ao modelo neoliberal, representado pela tendência de "cultura e mercado".

\section{Considerações Finais}

Talvez se possa identificar como bases
fundamentais dessa concepção de política cultural a democratização, a descentralização e a pluralidade. Democratização não só dos acessos aos bens culturais, ainda que isso seja essencial, mas principalmente a democratização da gestão, com a participação efetiva da sociedade civil, por meio de sua implantação de Conselhos e ampliação 
dos espaços de participação. Descentralização no sentido de romper com a separação geográfica centro-periferia. O fundamental da prática de descentralização é fomentar políticas que estimulem a renovação de hábitos culturais entre os moradores, a invenção de novas formas de sociabilidade, para dar espaço à criação de novos sujeitos culturais que se percebem como produtores de cultura e não apenas consumidores. Quanto à pluralidade, uma política cultural que se pretende democrática deve deixar sobressair as diferenças, as várias faces da cultura. "O que importa é que as pessoas descubram que podem sonhar. E porque sonham podem criar." (VARES, 1995, p. 61).

Essas questões sugerem a reflexão a respeito da política cultural como um exercício de democracia, de participação política, de ampliação dos espaços culturais abertos à população, não apenas na perspectiva de expectadores/consumidores, mas também de cidadãos com capacidade de interferir no processo de produção das políticas culturais. Essa concepção de política cultural parece colocar a política a serviço da democratização da cultura; apresenta-se como uma possibilidade de administração da cultura na qual se consideram as especificidades da área e envolve em seus processos participantes da vida cultural oriundos dos diversos segmentos sociais (artistas, intelectuais, dirigentes e funcionários de instituições culturais e cidadãos).

$\mathrm{Na}$ perspectiva da cidadania cultural, parte-se da atuação no âmbito da cultura, mas vislumbra em seu horizonte a transformação de mentalidades e, portanto, da cultura política. Assim, ela extrapola a esfera cultural com vistas à construção de uma verdadeira sociedade democrática.
BOBBIO, N. Teoria geral da política: a filosofia política e as lições dos clássicos. Rio de Janeiro: Campus, 2000.

CHAUI, M. Cultura política e política cultural. Estudos Avançados, São Paulo, v. 9, n. 23, p. 71-84, jan./abr. 1995.

- Política cultural, cultura política e patrimônio histórico. In: CUNHA, M. C. P. (Org.). Direito à memória: patrimônio histórico e cidadania em São Paulo. São Paulo: Departamento de Patrimônio Histórico, 1992. p. 37-46.

CHAUI, M.; CANDIDO, A.; ABRAMO, L.; MOSTAÇO, E. Política cultural. Porto Alegre: Mercado Aberto/Fundação Wilson Pinheiro, 1985.

COELHO, T. Dicionário crítico de política cultural. São Paulo: Iluminuras, 1997.

FEIJÓ, M. C. O que é política cultural. 5. ed. São Paulo: Brasiliense, 1992.

GOHN, M. G. O protagonismo da sociedade civil: movimentos sociais, ONGs e redes solidárias. 2. ed. São Paulo: Cortez, 2008.

PIOVESAN, F. Direitos sociais, econômicos e culturais e direitos civis e políticos. Sur: Revista Internacional de Direitos Humanos, São Paulo, v. 1, n. 1, p. 20-47, 2004.

SILVA, J. A. Da ordenação constitucional da cultura. São Paulo: Malheiros, 2001.

VARES, L. P. P. A política cultural democrática. In: ENCONTRO INTERMUNICIPAL DE CULTURA, 1995, Belo Horizonte. Anais... São Paulo: Pólis, 1995.

\section{Referências}

ADORNO, T. W. Cultura y administracion. In: ADORNO, T. W.; HORKHEIMER, M. Sociologica. Madri: Taurus, 1971. p. 122-146. 